DOI: https://doi.org/10.14232/actahisp.2021.26.157-160

\title{
CINE E HISTORIA EN AMÉRICA LATINA
}

\author{
BENCE PATKós \\ Universidad de Szeged, Hungría
}

Lénárt, András (2020):

Film és történelem Latin-Amerikában. A 20. század a filmtörténet tükrében

[Cine e historia en América Latina. El siglo 20 en el espejo de la historia del cine]. Szeged: JATEPress, 142 páginas. ISBN 978-963-315-454-0

András Lénárt, autor de varios artículos y una monografía dedicados a la relación entre el cine y la historia y a la historia del cine hispánico, profundiza en su nuevo libro en el análisis del nexo entre el cine y la historia en América Latina. La monografía fue publicada en húngaro por la editorial JATEPress en 2020. El libro de Lénárt no es una historia del cine latinoamericano habitual. Pese a que podemos conocer la relación entre Hollywood y el cine latinoamericano, algunas obras teóricas de cineastas que influían en el cine del continente, y mediante ellas las tendencias del séptimo arte en el territorio, no podemos leer sobre la biografía y obra de los directores de la región, y tampoco podemos encontrar reseñas o artículos estéticos cinematográficos, ya que la intención del historiador no fue esta. Lénárt nos ofrece una historia de cine totalmente diferente.

Analizar las relaciones entre la historia y el cine es una de las tendencias historiográficas más recientes y cada vez más aceptadas en las ciencias históricas en el siglo XXI. El cine a través de sus películas, como fuentes audiovisuales del siglo XX, nos ofrece un punto de partida especial para conocer mejor un período de un país. Observando el funcionamiento y la política de la industria del cine, el porqué y el cómo de la representación de diferentes acontecimientos, personajes históricos de la historia del continente o de un país en la pantalla, podemos entender mejor los objetivos de los cineastas y políticos de la cultura, sean el entretenimiento, la ideología o bien la influencia en la memoria histórica colectiva de una sociedad, siempre en concordancia con las circunstancias políticas del momento, transformándola según sus intenciones. Esta es la meta de Lénárt también: analizar los nexos entre un período histórico determinado, el siglo XX, y su representación artística en el cine, profundizando en los acontecimientos y cuestiones principales de la época histórica estudiada. Estos temas abarcan la memoria histórica de los eventos destacados del continente, las relaciones internacionales y los problemas sociales. Enfocándonos en los elementos mencionados, podemos tener una idea clara de la sociedad en la que nació la película, de sus características sociales, de su actitud hacia un evento o figura histórica, de su cosmovisión: ¿cuáles son los temas recurrentes?, ¿cómo es su 
representación? András Lénárt se comprometió a encontrar las respuestas a estas peguntas y las conexiones entre la sociedad, el cine y la política.

Tras una breve introducción teórica en la que conocemos las tendencias e influencias principales que formaban el cine latinoamericano, podemos leer sobre seis temas diferentes, elegidos por el autor mismo, en siete capítulos. Estos son los siguientes: los antecedentes del siglo XX (la América Latina colombina y los movimientos de independencia), la guerra hispano-estadounidense y sus consecuencias en el siglo XX, las relaciones cinematográficas interamericanas (dividido en dos partes: las versiones hispanas de Hollywood y la política de buena vecindad), los robos de niños en las dictaduras (especialmente en Argentina), el golpe de estado en Chile y la dictadura de Pinochet y, por último, la historia cubana del siglo XX en las películas recientes. Cada uno de los capítulos sigue la misma estructura. Primero, podemos leer sobre el contexto histórico y artístico y luego sobre el análisis de las películas elegidas por el historiador para presentar las características principales de la representación artística de los temas antes mencionados.

En primer lugar observamos el pasado histórico, la época colonial, las diferentes películas nacidas en torno a la figura de Cristóbal Colón, el descubrimiento de América y la conquista del nuevo mundo y sus protagonistas. En la segunda parte del capítulo conocemos a los protagonistas de las guerras de independencia del siglo XIX. El gran mérito de esta unidad es que Lénárt no solo analiza las películas recientes de países europeos, latinoamericanos y de los Estados Unidos, sino que recorre las obras del cine silente también. Además, aparte de las películas, el autor analiza incluso documentales y series, llamando nuestra atención sobre las tendencias básicas y los fallos históricos (a veces cometidos con intención) de las obras. Gracias a este recorrido, podemos comprender cómo cambiaba la opinión sobre un acontecimiento y un personaje (sea Colón mismo o un conquistador) según épocas y países, y cómo la política se aprovechaba de un hecho histórico según sus objetivos mediante los filmes, ocultando, destacando o a veces transformando elementos del pasado lejano.

En el segundo capítulo conocemos la representación de la guerra hispanoestadounidense y sus consecuencias en el siglo XX. En esta unidad el historiador compara las diferentes narrativas cinematográficas del mismo acontecimiento: conocemos la imagen estadounidense, la española y la cubana, lo que otorga un enfoque interesante a esta parte, ya que son tres pensamientos totalmente diferentes sobre el mismo suceso. Incluso escribe no solo sobre las películas, sino también sobre las grabaciones originales de la guerra, ya que en 1898, cuando estalló la guerra, los bandos ya disponían de cámaras, así que se han conservado cortometrajes sobre la guerra de la que Lénárt también informa a los lectores. En cuanto a los Estados Unidos podemos ver que un leitmotiv de su cine es el papel de los Rough Riders en la guerra, que fue una caballería voluntaria bajo la comandancia del presidente posterior, Theodore Roosevelt. Es obvio que durante y después de su presidencia nacieron películas que destacan su figura con un matiz heroico. Las 
películas que trataban el papel de los jinetes influían en la memoria colectiva de la sociedad estadounidense de modo que se convirtieron en héroes nacionales y emblemáticos, y determinaron cómo se presentaría al ejército estadounidense y las batallas en las que se veía involucrado. Sin embargo, pese a que España fue el otro participante del conflicto, desde que el país vivió la guerra como tragedia nacional, apenas apareció el tema en el cine español, solo cuando los intereses políticos motivaban los rodajes del tema. Las dos piezas clave del cine que adaptan la guerra son la Raza y Los últimos de Filipinas, dos obras propagandísticas de la dictadura de Franco. En el caso de la Raza, la guerra sirve como fondo para ver la historia familiar idealizada del Caudillo, mientras que en Los últimos de Filipinas vemos el asalto de la ciudad de Baler en las Islas Filipinas y nos enteramos del heroísmo de los soldados españoles. No obstante, es curiosa la representación positiva de los Estados Unidos, pero Lénárt nos explica que eso se debe a que tras la Segunda Guerra Mundial España intentaba fomentar buenas relaciones con la superpotencia occidental, aunque en la guerra de 1898 lucharon uno contra el otro. Finalmente, conocemos la versión cubana de los acontecimientos que nació en la Cuba de Fidel Castro e intentaron presentarlos como un paso adelante en la lucha eterna por la independencia cubana cuya culminación sería la revolución de 1959. La presentación triple de los diferentes puntos de vista realizados en varios momentos de los distintos países, los temas principales de los filmes, sus comparaciones y el hecho de que no relata solamente las películas, sino los documentales y los cortos del rudimentario género noticiario también aumenta el nivel del capítulo.

Los dos capítulos siguientes introducen las relaciones cinematográficas interamericanas, primero en el período de entreguerras y después de la Gran Depresión de 1929. En el primer período, como Hollywood tenía el monopolio del rodaje de películas, los Estados Unidos intentaban beneficiarse de esta época y empezaron a grabar versiones hispanas (entre otras) de los filmes que estaban rodando en los EE.UU., pero con actores hispanohablantes. El objetivo principal de estas películas fue el entretenimiento, sin embargo, debido a la mala calidad de las obras y a los dialectos diferentes que se mezclaban, se produjo gran polémica y descontento por parte del público. Esta política de cine cambió tras la crisis económica de 1929, ya que los líderes políticos estadounidenses se dieron cuenta de que tenían que frenar el avance nazi y fascista en el continente americano, así que emprendieron una nueva política cultural cuyo objetivo fue la mejora de la imagen de los Estados Unidos en América Latina y, a la vez, la presentación de una visión menos estereotípica sobre América Latina en los Estados Unidos. Esta unidad, como trata más el tema de la política cinematográfica estadounidense y analiza menos películas que antes o después en el libro, aparentemente rompe un poco la continuidad lógica de la monografía. Aun así, es un capítulo que contribuye a entender mejor cómo el cine de Hollywood influía no solo en el territorio, sino mundialmente en la cosmovisión del público sobre América Latina a través de sus películas. 
Los tres últimos capítulos tratan de tres acontecimientos históricos, políticos y sociales de América Latina. Primero, podemos leer sobre la representación cinematográfica de la apropiación de menores en las dictaduras, especialmente en Argentina. Naturalmente, la película más profundamente analizada es La historia oficial de Luis Puenzo que es una forma de enfrentarse al horror de la dictadura argentina (1976 y 1983). En el capítulo, el autor nos ofrece un recorrido histórico excelente con explicaciones profundas y bien estructuradas en el que puede situar perfectamente las películas analizadas. Segundo, el autor se encarga del análisis del golpe de estado chileno y de la dictadura de Pinochet en el cine. Tanto en el caso argentino como en el chileno, la excelente descripción histórica es seguida por la descripción de varias películas chilenas y extranjeras que se ocupan de la representación de la figura de Salvador Allende, del golpe de estado y de la dictadura de Pinochet. Los directores más destacados son Helvio Soto, Patricio Guzmán y Pablo Larraín. Aparte del análisis de las películas de los cineastas antes mencionados, Lénárt ofrece de nuevo una amplia lista de películas y series extranjeras recientes que abordan el tema de la dictadura de Pinochet y sus terribles crímenes cometidos contra la sociedad chilena o contra figuras famosas del país, como Víctor Jara. Por último, conocemos el cine cubano después de la revolución de 1959. Lénárt nos presenta el fondo históricopolítico de la Cuba de Fidel Castro y da información teórica del nuevo cine cubano también, creando los marcos entre los que tenemos que comprenderlo y analizarlo. A través del análisis de las películas de Miguel Coyula, Daniel Díaz Torres y Pavel Giroud se puede entender mejor la realidad cubana, los problemas sociales e históricos del país caribeño. El historiador enumera también las películas extranjeras, sobre todo estadounidenses, que se interesaban por la cuestión cubana o por los intereses americanos anteriores a la revolución o por la situación cubana durante la guerra fría. En estos últimos tres capítulos, András Lénárt nos ofrece un amplio abanico de películas, sean argentinas, chilenas, cubanas o de otras nacionalidades, que tratan los temas de las historias recientes, contemporáneas de los países, cuyos temas siguen siendo vivos e influyentes en las sociedades de los estados latinoamericanos. Las introducciones históricas, la comparación extraordinaria de la representación cinematográfica del caso argentino, chileno y cubano con las otras versiones convierten las tres últimas unidades en las más cautivadoras del tomo.

Hasta hoy en Hungría apenas editaron libros que trataban la historia del cine latinoamericano, solo había algunos artículos en las principales revistas de cine y varios capítulos en algunos libros. Ahora, después de su monografía sobre el cine del franquismo, András Lénárt ha vuelto a publicar un tomo que se fundamenta en sus investigaciones, siendo el primer libro húngaro que nace a base de estudios propios en el tema de la relación entre el cine y la historia de América Latina. El fruto del trabajo es una obra que resulta ser interesante y útil tanto para los expertos como para los cinéfilos. 